\title{
Effect of fenpropimorph, prochloraz and tebuconazole on growth and production of T-2 and HT-2 toxins by Fusarium langsethiae in oat-based medium
}

Eva M. Mateo ${ }^{a, b}$, F.M. Valle-Algarra ${ }^{b}$, R. Mateo ${ }^{b}$, M. Jiménez ${ }^{b}$ and N. Magan ${ }^{a^{*}}$

${ }^{a}$ Applied Mycology Group, Cranfield Health, Cranfield University, Cranfield, Bedforshire MK43 OAL, UK; ${ }^{b}$ Department of Microbiology and Ecology, Valencia University, Dr. Moliner 50, 46100-Burjassot, Valencia, Spain

* Corresponding author:

Prof. N. Magan, Applied Mycology Group, Cranfield Health, Cranfield University, Cranfield, Bedfordshire MK43 OAL, UK; Email: n.magan@cranfield.ac.uk

Keywords: Fusarium langsethiae, fungicides, oat-based medium, ED $\mathrm{D}_{50}, \mathrm{ED}_{90}$, growth rate, T-2 toxin, HT-2 toxin.

\section{Abstract}

Fusarium langsethiae has been isolated from infected cereals in central and northern Europe where it has been identified in the last decade as the main species involved in the occurrence of high levels of T-2 and HT-2 toxins, mainly in oats. The efficacy of three fungicides (prochloraz, tebuconazole, fenpropimorph) for controlling growth of two strains of $F$. langsethiae isolated from oats was examined at 0.96 and $0.98 \mathrm{a}_{\mathrm{w}}$ at 15,20 and $25 \stackrel{\circ}{\circ}$ on oat-based media. The concentrations necessary for 50 and $90 \%$ growth inhibition $\left(E D_{50}\right.$ and $E D_{90}$ values) were determined. The effect on the trichothecene type A mycotoxins T-2 and HT-2 were also determined. Without fungicides both strains grew faster at 0.98 than at $0.96 \mathrm{a}_{\mathrm{w}}$ and the influence of temperature on growth rates was $25>20>15 \stackrel{\circ}{ } \mathrm{C}$. Prochloraz and tebuconazole were more effective than fenpropimorph against $F$. langsethiae. Strain, temperature and type of fungicide significantly influence the $E D_{50}$ and $E D_{90}$ values for growth. The concentration ranges under different environmental conditions were: prochloraz (0.030.1 and 0.3-1.5), tebuconazole (0.06-0.9 and 1.3-8.2), and fenpropimorph (22-59 and $\left.125-215 \mathrm{mg} \mathrm{l}^{-1}\right)$. Production of T-2 and HT-2 toxins was influenced by temperature, $\mathrm{a}_{\mathrm{w}}$, type of fungicide and dose. Levels of T-2 were usually higher than those of HT-2 under 
the same conditions. The biosynthesis of T-2 toxin increased after 10 days incubation, but was reduced with decreasing temperature and increasing fungicide dose. At 0.98 $a_{w}$ T-2 levels increased in cultures containing fenpropimorph while at $0.96 a_{w}$ the toxin concentrations increased in response to the other two fungicides. Low doses of prochloraz or tebuconazole enhanced toxin production when compared with untreated cultures for strain 2004-59 at $0.96 \mathrm{a}_{\mathrm{w}}$ and 20-25 ${ }^{\circ} \mathrm{C}$. HT-2 was hardly detectable in the treatments with prochloraz or tebuconazole at $0.98 \mathrm{a}_{\mathrm{w}}$. This is the first study on the effect of these anti-fungal compounds on control of growth of $F$. langsethiae and effects on T-2 and HT-2 toxins in oat-based media.

\section{Introduction}

Fusarium head blight $(\mathrm{FHB})$ is a wide-spread destructive disease of small-grain cereal crops caused by a wide number of Fusarium spp. and some Microdochium spp. (Xu et al., 2005). Fusarium spp. in general reduces grain yield and/or contaminates the grain with a range of toxic metabolites detrimental to human and animal health.

Fusarium langsethiae has been isolated from infected oats, wheat and barley in central and northern Europe (Torp and Adler, 2004; Torp and Nirenberg, 2004). This species, with the morphological characteristics of Fusarium poae and metabolic profile of Fusarium sporotrichioides (Torp and Nirenberg, 2004; Schmidt et al., 2004; Thrane et al., 2004; Wilson et al., 2004, Yli-Mattila et al., 2004, 2008), was identified a decade ago (Torp and Langseth, 1999). However, it does not produce any visible symptoms, which makes colonisation assessment and effect of fungicides difficult to test in small grains. Although a small percentage of wheat ears with infected 'glume spots' thought to have been caused by $F$. langsethiae in the field have been observed in Austria (Adler and Torp, 2004), F. langsethiae can readily be isolated from symptomless oats, wheat and barley grains. The epidemiology of this specie is not understood and host plant preference is unknown, though recent results suggest that $F$. langsethiae may have developed some host preference for oats (Imathiu et al., 2009).

$F$. langsethiae has been involved in the production of high levels of T-2 and HT2 mycotoxins in cereals in Norway (Langseth and Rundberget, 1999; Torp and Langseth, 1999) and in oats in the UK (Edwards, 2007), where recent studies have shown a high incidence of both toxins in wheat, barley and especially in oats (Edwards, 2009a, 2009b, 2009c; Scudamore et al., 2007, 2009). The highly toxic type A trichothecenes T-2 toxin and its deacetylated form HT-2 toxin are of special interest because T-2 toxin has been shown to inhibit DNA, RNA and protein synthesis and to induce DNA fragmentation characteristic of apoptosis (Beasley, 1989; Canady et al., 
2001; Prelusky et al., 1994; Schuhmacher-Wolz et al., 2010). T-2 and HT-2 mycotoxins, in unprocessed cereals and by products are currently being considered for legislation in the EU (European Commission, 2006).

The main factors that influence fungal growth and mycotoxin production are temperature, water activity $\left(\mathrm{a}_{\mathrm{w}}\right)$ and presence of anti-fungal substances (Aldred and Magan, 2004; Edwards, 2004, Llorens et al., 2004a, 2004b; Logrieco and Visconti, 2004; Magan and Aldred, 2007; Magan et al., 2002; Medina et al., 2007a, 2007b; Ramírez et al., 2004, 2006). A significant focus has been on the development and use of fungicides to prevent and control infection of pathogenic Fusarium spp. during ripening of small grain cereal crops. Less attention has been paid, in practice, to the effect that such fungicide applications may have on mycotoxin production. This is important as it has been observed that sub-lethal doses of some fungicides may lead to a stimulation of trichothecene production by Fusarium species (D'Mello et al., 1997, 1998; Hope et al., 2002; Mathies et al., 1999; Moss and Frank, 1985; Placinta et al., 1996; Ramírez et al., 2004). It is surprising that these previous reports, with the exception of Hope et al. (2002) and Ramírez et al. (2004), took no account of the interactions between the efficacy of the fungicides and key environmental factors, such as $a_{w}$ or temperature.

Fungicide applications pre-harvest are a reality whether in intensive or sustainable cereal production systems. Fusarium species colonising ripening cereals will thus be exposed to azole fungicides, such as prochloraz (imidazole), or tebuconazole (triazole) and morpholines, such as fenpropimorph, in agricultural environments (Serfling et al., 2007). In describing the response of an isolate to a fungicide, an $\mathrm{EC}_{50}$ (50\% effective concentration) or $\mathrm{ED}_{50}(50 \%$ effective dose) value is usually given. This is the concentration or dose that reduces growth rate to $50 \%$ compared with that observed in the absence of fungicide. An $E C_{90}$ or $E D_{90}$ value is sometimes also given. It provides additional information about growth over a wider range of fungicide concentrations (Serfling et al., 2007; Tzatzarakis et al., 2001). Thus, these parameters deal with the efficacy to control fungal growth but their impact or relationship to the level of mycotoxin accumulation in the substrate has not been studied in detail (Pateraki et al., 2007). Prochloraz, tebuconazole and fenpropimorph are extensively applied in agriculture to control fungal growth in cereals and other crops in many European countries. So far, no study has been carried out to examine the effect of these anti-fungal agents on the growth of $F$. langsethiae strains or their ability to produce T-2 and HT-2 toxins. 
Therefore, the objectives of this study were to assess the efficacy of prochloraz, tebuconazole, and fenpropimorph in an oat-based medium, under different $a_{w} /$ temperature regimes on the control of (i) growth of two strains of $F$. langsethiae isolated from oats from different countries and (ii) T-2 and HT-2 production by these strains. The $E D_{50}$ and $E D_{90}$ values for fungicides in relation to growth and toxin production under different $\mathrm{a}_{\mathrm{w}} \times$ temperature conditions were determined.

\section{Materials and Methods}

\subsection{Fungal strains and growth conditions}

Two strains of F. langsethiae, 2004-59 and M562, isolated from oats in UK and Sweden, respectively, were used. These strains are held in the Applied Mycology Group Culture Collection (Cranfield University, UK). They were kindly provided by Prof. S. Edwards, Harper Adams University College, U.K. and Dr M. Olsen, Swedish Food Authority, Sweden. Cultures were preserved in $15 \%$ glycerol at $-20 \stackrel{\circ}{ } \mathrm{C}$. Before carrying out the study of ecological factors on growth and T-2 and HT-2 accumulation, the strains were grown on 3\% oat agar. The culture medium was prepared by boiling $30 \mathrm{~g}$ of oats kernels in pure water for $1 \mathrm{~h}$. After filtration, the liquid was brought to $1 \mathrm{I}$ and $2 \%$ $\mathrm{w} / \mathrm{v}$ of agar was added. The mixture was autoclaved at $115^{\circ} \mathrm{C}$ for $30 \mathrm{~min}$ and poured into Petri dishes. The strains were inoculated on the centre of $9 \mathrm{~cm}$ Petri plates and incubated at $25 \stackrel{\circ}{\circ}$ for 7 days. These fresh cultures were used to prepare inocula for further experiments on efficacy of fungicides on fungal growth and toxin production.

\subsection{Modification of media with fungicides at different $a_{w}$ conditions}

The active ingredient, product name, concentration and company of the fungicides used in this study were the following: fenpropimorph (Funbas ${ }^{\circledR}$, EC $750 \mathrm{~g}$ a.i./l, BASF Crop Protection, Spain); prochloraz (Dogma ${ }^{\circledR} 400 \mathrm{~g}$ a.i/l, Industrias Afrasa S.A., Paterna, Valencia, Spain); tebuconazole (Folicur ${ }^{\circledR} 250 \mathrm{~g}$ a.i./l, Bayer CropScience, Paterna, Valencia, Spain). Diluted solutions of the fungicides were prepared by mixing appropriate amounts of each fungicide (based on concentration of the a.i.) in sterile deionised water and used immediately after preparation.

A solid medium containing oat extract was prepared as indicated in Section 2.1. The water activity of the media were adjusted to 0.98 and 0.96 with glycerol and, after autoclaving (115 ${ }^{\circ} \mathrm{C}, 20 \mathrm{~min}$ ), was let to cool to about $50{ }^{\circ} \mathrm{C}$ (Medina and Magan, 2010b). The fungicides were then added to obtain the target concentrations. Flasks of molten media were thoroughly shaken, prior to pouring into $9 \mathrm{~cm}$ sterile Petri dishes, to ensure that an even dispersion of the fungicide treatment was obtained. Preliminary 
experiments were performed to choose the range of concentrations for each fungicide to be added to obtain dose response curves. Based on these assays the doses used were: prochloraz $(0.01,0.1,0.3,0.7,0.9,1.5 \mathrm{mg} / \mathrm{l})$, tebuconazole $(0.1,0.3,0.5,0.7$, $0.9,1.5$, and $2 \mathrm{mg} / \mathrm{l}$; additionally, 4,8 and $12 \mathrm{mg} / \mathrm{l}$ were tested for $0.96 \mathrm{a}_{\mathrm{w}}$ ) and fenpropimorph (10, 20, 25, 30, 50, 90, 150 and $180 \mathrm{mg} / \mathrm{l}$; additionally, 40 and 70 were assayed at $0.98 \mathrm{a}_{\mathrm{w}}$, and 200 and $230 \mathrm{mg} / \mathrm{l}$ were tested for strain M562 at $0.98 \mathrm{a}_{\mathrm{w}}$ ).

All media, with and without fungicides, were inoculated centrally with a 3-mm diameter agar disk taken from the margin of a 5-7-day-old growing colonies. Inoculated Petri plates of the same $a_{w}$ were enclosed in sealed plastic containers together with beakers of a glycerol-water solution matching the same $a_{w}$ as the treatment to maintain a constant equilibrium relative humidity $(\mathrm{ERH})$ inside the boxes. The experiments were carried out in triplicate. Treatments were incubated $15^{\circ} \mathrm{C}, 20^{\circ} \mathrm{C}$ and $25^{\circ} \mathrm{C}$ for 10 days.

\subsubsection{Growth evaluation}

Assessment of growth was made every day during the incubation period by measurement of two diameters of the growing colonies at right angles to each other until the colony reached the edge of the plate. The radii of the colonies were plotted against time, and linear regression applied in order to obtain the growth rate $(\mathrm{mm} / \mathrm{day})$ as the slope of the line. The growth rates were plotted and the $\mathrm{ED}_{50}$ and $\mathrm{ED}_{90}$ concentrations calculated by comparison with the controls at each temperature and $a_{w}$ level.

\subsubsection{Chemical analysis}

Reagents and standards

Standards of T-2 and HT-2 toxins were supplied by Sigma (Sigma-Aldrich, Alcobendas, Spain). Acetonitrile and methanol were supplied from J.T. Baker (Deventer, The Netherlands). Pure water was obtained from a Milli-Q system (Millipore Co., Billerica, MA, USA). All solvents were HPLC grade.

\section{Extraction of T-2 and HT-2 toxins from the F. langsethiae cultures}

Approx. 5-6 agar discs were taken from the replicates and treatment agar plates using a cork borer and placed in previously weighed $2 \mathrm{ml}$ Eppendorf safe-lock tubes and then reweighed. This provided about $0.75 \mathrm{~g}$ agar/culture for extraction. A total of 3 replicates per treatment and controls, respectively, were collected and analysed for T-2 and HT-2 toxins as described by Medina et al. (2010a). 


\section{Chromatographic analysis}

The LC system consisted of a Waters 600E system controller, a Millipore Waters 717 Plus autosampler and a Waters 996 Photodiode array detector (DAD) (Waters, Milford, MA, USA).

A volume of $50 \mu \mathrm{L}$ of the extract was injected into the LC system. T-2 and HT-2 toxins were separated using a C18 Zorbax Eclipse Plus ${ }^{\circledR}(150 \times 4.6 \mathrm{~mm}, 3.5 \mu \mathrm{m})$ (Agilent Technologies, Waldbronn, Germany), with a guard column of the same material. Analysis was performed in the gradient mode using two solvents (Medina et al., 2010a).

\section{Statistical Analysis}

Statistical analysis was performed using Statgraphics Centurion XV.2.11 (Statpoint Inc., VA, USA). Multifactor ANOVA and post hoc analysis of factors with more than two levels (Duncan's test of multiple comparisons) were applied to data. $A$ $95 \%$ confidence level was used to assess influence of individual and interacting treatments.

\section{Results}

3.1. Effect of fungicides on growth of the two strains of $\mathrm{F}$. langsethiae used in this study.

The relative growth of the two strains was initially examined in relation to the treatment conditions of $a_{w} \times$ temperature (Fig. 1). This shows that growth was favoured by temperature (growth rates increase in the order $25>20>15^{\circ} \mathrm{C}$ ) and was faster at 0.98 than $0.96 \mathrm{a}_{\mathrm{w}}$, regardless of temperature. The statistical analyses using ANOVA showed that single factors of $a_{w}$ and temperature were significant $(P<0.05)$ while strain differences and interacting factors were not. Duncan's test showed three homogeneous non-overlapping groups with regard to temperature.

Figs. 2 and 3 show the effects of fenpropimorph and the two azoles (prochloraz and tebuconazole), respectively, on the growth rate (GR, $\mathrm{mm} /$ day) of the two strains of $F$. langsethiae on oat-based media under the all the treatment conditions assayed. In general, there was a decrease of the RGR as the fungicide dose was increased regardless of $a_{w}$, temperature and strain. These data were used to calculate the $E D_{50}$ and $\mathrm{ED}_{90}$ of each fungicide, which are shown in Table 1

For fenpropimorph, the $E D_{50}$ and $E D_{90}$ values were in the ranges 22-59 and 125-215 mg/l, respectively (Table 1). Both indices increased with temperature so that this fungicide was more effective at 15 than $25^{\circ} \mathrm{C}$. ANOVA revealed that the $\mathrm{ED}_{50}$ was 
significantly affected $(P<0.05)$ by temperature but not by $a_{w}$ or the strain. However, the $\mathrm{ED}_{90}$ was significantly affected by all single factors as well as by the interaction $\mathrm{a}_{\mathrm{w}} \times$ strain and the Duncan's test placed each temperature in a separate homogeneous group.

For prochloraz, Table 1 shows the ranges of $\mathrm{ED}_{50}(0.03-0.1 \mathrm{mg} / \mathrm{l})$ and $\mathrm{ED}_{90}$ (0.3$1.5 \mathrm{mg} / \mathrm{l})$. There were significant differences $(P<0.05)$ among the $E D_{50}$ related to $a_{w}$, temperature and the interaction temperature $\times a_{w}$. Temperature originates three homogeneous, non-overlapping groups (Duncan's test). $E D_{90}$ was influenced by temperature, $a_{w}$ and strain but there were interactions between $a_{w}$ and strain or temperature. Efficacy was higher at 15 than $20-25{ }^{\circ} \mathrm{C}$.

For tebuconazole, the $\mathrm{ED}_{50}$ and $\mathrm{ED}_{90}$ values were in the ranges $0.06-0.9$ and 1.3-8.2 mg/l, respectively (Table 1$)$. The $E D_{50}$ was significantly affected only by $a_{w}(P<$ 0.05). The fungicide was more effective at $0.98 \mathrm{a}_{w}$. However, the $E D_{90}$ was significantly influenced by temperature, $a_{w}$ and the interaction $a_{w} \times$ temperature. The Duncan's test applied to $\mathrm{ED}_{90}$ shows that control of growth was better at 15 than $20-25^{\circ} \mathrm{C}$.

ANOVA of all the data including class of fungicide, $a_{w}$, strain and temperature revealed that these factors (except for $a_{w}$ ) significantly influenced $(P<0.05)$ the $E D_{50}$ values. The interactions between type of fungicide and temperature or type of fungicide and strain were also significant. The average $\mathrm{ED}_{50}$ of fenpropimorph was higher than that for the azole fungicides (Table 1), which clustered together in a single homogeneous group (Duncan's test). With regard to temperature effects on the $\mathrm{ED}_{50}$, the Duncan's test showed two homogeneous groups ( $15^{\circ} \mathrm{C}$ and $20-25^{\circ} \mathrm{C}$ ). With regard to the $E D_{90}$, the four single factors and their interactions were also statistically significant $(P<0.05)$. There were differences between efficacy of the fungicides $(P<$ 0.001). The Duncan's test placed each fungicide and each temperature in a separate non-overlapping group.

To summarise, overall prochloraz was the most active antifungal agent to control growth of $F$. langsethiae. Tebuconazole was about 4-6 times less effective than prochloraz, but differences are significant only regarding the $E D_{90}$. Fenpropimorph was by far the least active fungicide (100-500 times less effective than prochloraz). Influence of $a_{w}$ and strain was not conclusive as it was generally affected by interactions. However, efficacy of fungicides was always higher at $15^{\circ} \mathrm{C}$ than $25^{\circ} \mathrm{C}$.

\subsection{Effect of fungicides on T-2 and HT-2 mycotoxin production by F. langsethiae} strains 
Fig. 4 shows the effect of $\mathrm{a}_{\mathrm{w}}$ and temperature on T-2 and HT-2 production by both strains of $F$. langsethiae at different $a_{w} /$ temperature regimes in control cultures. This shows that T-2 toxin was predominantly produced by the strains with significantly less HT-2 toxin produced regardless of environmental conditions. Overall, strain M562 produced more T-2 than strain 2004-59 under the same conditions. The maximum T-2 level $(11.6 \mu \mathrm{g} / \mathrm{g})$ was found in control cultures of strain M562 incubated at $0.98 \mathrm{a}_{\mathrm{w}}$ and $25^{\circ} \mathrm{C}$ (see Fig. 4). Overall, T-2 concentration was always lower a $15^{\circ} \mathrm{C}$ than at 20 or 25 ${ }^{\circ} \mathrm{C}$. Levels of $\mathrm{HT}-2$ were $<1.5 \mu \mathrm{g} / \mathrm{g}$ and this toxin was sometimes undetectable in cultures of strain M562.

The hypothesis of a normal distribution of mycotoxin data cannot be rejected with 95\% confidence level according to the Shapiro-Wilks test. However, transformation of data using the expression log $(x+1)$, where $x$ is toxin concentration was carried out to improve normality. Multifactor ANOVA (without interaction, as interaction was not significant) revealed that T-2 concentration in control cultures is significantly affected $(P \leq 0.05)$ by $a_{w}$ (less concentration at $\left.0.96 a_{w}\right)$ and temperature (less concentration at $15^{\circ} \mathrm{C}$ than at $25^{\circ} \mathrm{C}$ ) but not by the strain. Duncan's test showed two homogeneous overlapping groups with regard to the influence of temperature (15$20 \stackrel{\circ}{\circ}$ and $\left.20-25^{\circ} \mathrm{C}\right)$. HT-2 production was not significantly affected $(\mathrm{P}>0.05)$ by any of the factors.

Fenpropimorph: Fig. 5 shows the levels of T-2 and HT-2 in cultures of both strains in oat-based medium after 10 incubation days in presence of fenpropimorph. The highest level of T-2 $(6.6 \mu \mathrm{g} / \mathrm{g})$ was produced by strain M562 at $10 \mathrm{mg}$ fenpropimorph/l, $0.98 \mathrm{a}_{\mathrm{w}}$ and $25 \stackrel{\circ}{ } \mathrm{C}$. Overall, production of both toxins decreased when fungicide dose increased. T-2 production was reduced regarding untreated controls carried out under the same conditions at all doses. However, under some conditions $\left(0.96 \mathrm{a}_{\mathrm{w}}\right)$ a slight increase of T-2 toxin level when fungicide dose increased (from 10 to $25 \mathrm{mg} / \mathrm{l})$ was found.

Prochloraz: Fig. 6 shows toxin accumulation data in presence of prochloraz. The maximum T-2 toxin level $(3.7 \mu \mathrm{g} / \mathrm{g})$ was found in cultures of strain M562 supplemented with $0.01 \mathrm{mg} / \mathrm{l}$ at $0.96 \mathrm{a}_{\mathrm{w}}$ and $25{ }^{\circ} \mathrm{C}$. In general, toxin levels were higher at $0.96 a_{w}$ than at $0.98 a_{w}$, and higher in cultures of strain M562 than strain 2004-59. These levels decreased with decreasing temperature and increasing dose. No toxin was detected a doses $>0.7 \mathrm{mg} / \mathrm{l}$. At $0.98 \mathrm{a}_{\mathrm{w}}$ detectable levels were found only at the two lowest doses. Interestingly, the $0.01 \mathrm{mg} / \mathrm{l}$ dose at $0.96 \mathrm{a}_{\mathrm{w}}$ and $20-25{ }^{\circ} \mathrm{C}$ seemed to promote T-2 production with regard to untreated cultures of strain 2004-59. 
Tebuconazole: The effect of tebuconazole on accumulation of these mycotoxins in oat-based medium is shown in Fig. 7. The maximum concentration of T-2 $(4.4 \mu \mathrm{g} / \mathrm{g})$ was recorded in cultures of strain 2004-59 at 0.96 $\mathrm{a}_{\mathrm{w}}, 25{ }^{\circ} \mathrm{C}$, and $0.1 \mathrm{mg}$ tebuconazole/l. Toxin levels were higher at $0.96 a_{w}$ than at $0.98 a_{w}$ (as happened with prochloraz) and both toxins were undetected in cultures supplemented with $>2.0 \mathrm{mg} / \mathrm{l}$. HT-2 was not usually detected at $0.98 \mathrm{a}_{\mathrm{w}}$. As in the case of prochloraz and unlike fenpropimorph, at low doses of tebuconazole T-2 production increased with regard to untreated cultures of strain 2004-59 at 0.96 $\mathrm{a}_{\mathrm{w}}$ and 20-25 ${ }^{\circ} \mathrm{C}$.

ANOVA of T-2 production data in presence of fenpropimorph indicated that strain, temperature, and fungicide dose significantly influenced $T-2$ production $(P<$ $0.05)$ although the interactions $a_{w} \times$ dose, $a_{w} \times$ temperature and strain $\times$ temperature were also significant. Strain M562 significantly produced more T-2 toxin than strain 2004-59. Overall, increasing temperature favoured toxin production and increasing fungicide dose caused a decrease in toxin accumulation. Duncan's test showed three homogeneous non-overlapping clusters related to temperature. HT-2 toxin production was significantly influenced by dose and $a_{w}$. The interactions strain $\times$ temperature and $a_{w} \times$ strain $\times$ temperature were also significant.

ANOVA of T-2 production data in presence of prochloraz showed that fungal strain did not significantly influence $\mathrm{T}-2$ level but the remaining single factors did. The interactions $a_{w} \times$ dose, $a_{w} \times$ temperature, and temperature $\times$ dose were also significant. Duncan's test classified the tested temperatures and doses into three different nonoverlapping clusters (for dose, $0.01,0.1$ and the remaining ones). HT-2 toxin production was influenced by $a_{w}$, dose and the interactions $a_{w} \times$ dose and $a_{w} \times$ dose $\times$ strain.

ANOVA and Duncan's test of T-2 production data in presence of tebuconazole gave similar results to those obtained in media amended with prochloraz. However, in the case of HT-2 toxin all factors significantly influenced HT-2 production: its level increased with temperature and strain M562 produced less toxin than strain 2004-59.

To summarise, prochloraz and tebuconazole were more effective than fenpropimorph with regard to the reduction of T-2 toxin production. Effectiveness increased with the concentration of each antifungal agent and with decreasing temperature in the order $15>20>25^{\circ} \mathrm{C}$. Prochloraz and tebuconazole were more effective at $0.98 a_{w}$ than at $0.96 a_{w}$ while fenpropimorph was on average equally effective at both values. Fungal strain influenced T-2 level only in the case of fenpropimorph. Concerning reduction of HT-2 toxin production, effectiveness also increased with the concentration of each fungicide and was higher at $0.98 a_{w}$ but did 
not change with temperature or strain, except for tebuconazole. The existence of interactions between the variables revealed by ANOVA enables to assume that there are complex relationships that govern the production of these mycotoxins in oat-based medium amended with any of the three fungicides tested.

\section{Discussion}

Some anti-fungals agents used in small grain cereals have been examined in detail for efficacy against strains of $F$. langsethiae in relation to both growth and production of T-2 and HT-2 toxins under different environmental conditions. This study has shown that there are complex interactions between abiotic factors fungicides and toxin production. There are differential effects on both growth and toxin which were clearly shown by the $E D_{50}$ and $E D_{90}$ values for the three fungicides tested. This study has provided new data that suggest that relevant changes in the response of the fungi to $a_{w}$ and temperature take place in the presence of sub-inhibitory concentrations of the assayed fungicides. Consequently, treatments with these anti-fungal substances might affect the natural presence and distribution of $F$. langsethiae and production of T-2 and HT-2 in cereals.

In the absence of fungicides (controls) and under the experimental conditions, both strains grow faster at $0.98 a_{w}$ than at $0.96 a_{w}$ and the order of growth rate is $25>20>15^{\circ} \mathrm{C}$. These results agree with the recent data on the influence of these parameters on growth profiles of 8 strains of $F$. langsethiae from northern Europe (Magan et al., 2011; Medina and Magan, 2010b). Production of T-2 and HT-2 in the absence of fungicides was also higher in the media where the values of $a_{w}$ and temperature were higher. These results also agree with previous reports (Kokkonen et al., 2010; Medina et al., 2011) and might explain differences in T-2/HT-2 contamination of cereals depending on the country of origin. Scudamore et al. (2009) have found higher contamination in samples from the UK and Ireland than in samples from Scandinavia.

Even when the studied fungicides were effective to control growth and production of T-2 and HT-2, overall, fenpropimorph was the least effective of the three fungicides examined with higher concentrations required to inhibit growth (high $\mathrm{ED}_{50}, \mathrm{ED}_{90}$ values). This chemical was more effective against other 
species, such as Microdochium nivale ( $\left.\mathrm{ED}_{50}=0.13 \mathrm{mg} / \mathrm{l}\right)$ (Debieu et al., 2000), although the assay conditions were different. This anti-fungal agent belongs to the morpholine group of sterol biosynthesis inhibitors (Campagnac et al., 2009; Debieu et al., 1992; Marcireau et al., 1990) and is widely used to control pathogens, such as powdery mildew, rusts and leaf blotch diseases of cereals (Leroux, 2003). The results of the present study show that the $E D_{50}$ of fenpropimorph against $F$. langsethiae is not significantly affected $(P>0.05)$ by the factors $a_{w}$, strain and temperature or their mutual interactions. However, the $E D_{90}$ is significantly affected by the three single factors and the interaction $a_{w} \times$ strain. These results provide interesting information that can be very useful to control $F$. langsethiae and other toxigenic fungi in cereals.

Like fenpropimorph, in general the azole-based compounds, prochloraz and tebuconazole, were more effective at 15 than 20-25 $\circ$ C. This may be important as this Fusarium species is known to cause problems in cooler climatic regions such as the UK, Ireland or Scandinavia, where ripening and slow drying can result in conducive conditions for this species to colonise oats. The $E D_{50}$ concentrations required to control growth were very similar for these two azoles. However, the $E_{90}$ value for prochloraz was lower than for tebuconazole suggesting better efficacy overall in controlling growth of this $F$. langsethiae. Previous studies with the efficacy of these fungicides against $F$. graminearum also suggested that prochloraz was more effective in vitro than in situ (Ramírez et al., 2004). However, this was on wheat. The $E D_{50}$ and $E D_{90}$ of prochloraz and tebuconazole were determined against the maize pathogen Colletotrichum graminícola (Serfling et al., 2007) and also showed that this pathogen was more sensitive to prochloraz than to tebuconazole. Moreover, this behaviour was similar in non-adapted and adapted strains to these fungicides. Thus, $E D_{50}$ and $E D_{90}$ of prochloraz against a non-adapted strain of C. graminicola was $0.004 \mathrm{mg} / \mathrm{l}$ and $0.087 \mathrm{mg} / \mathrm{l}$, respectively, while in the adapted strain these concentrations were 0.011 and $0.720 \mathrm{mg} / \mathrm{l}$, respectively. Against other Fusarium species on PDA the range was $0.24-6.5 \mathrm{mg} / \mathrm{l}$ (the less sensitive was $F$. crookwellense and the most sensitive was $F$. sporotrichioides) (Mullenborn et al., 2008). All these reports and the results obtained in the present study indicate that the efficacy of these fungicides is dependent on the 
fungal species, strain, ecological conditions and the interactions amongst all these factors. Azoles differing in structure but exhibiting the same mode of action are used to treat both fungal diseases of plants and medical mycoses. These anti-fungal agents interfere with the metabolism of fungal pathogens, mainly by inhibition of ergosterol biosynthesis (Hewitt, 2004). Studies on the efficacy of azoles on the growth of phytopathogenic and mycotoxigenic fungi on cereals are needed to find the optimal doses for a suitable control of these fungi and to minimise the risk of resistant strain build-up.

It is concluded that, in the presence of fenpropimorph, the highest levels of T-2 and HT-2 were obtained at $0.98 \mathrm{a}_{\mathrm{w}}$, which was also the most favourable value for fungal growth, both in controls and in the presence of the fungicide. Similar results were obtained in previous reports (Kokkonen et al., 2010; Medina et al., 2011) with $F$. langsethiae in absence of fungicides. The results obtained in the present study show that fenpropimorph added in the range 10$70 \mathrm{mg} / \mathrm{l}$ decreases production of T-2 and HT-2 with regard to controls but does not prevent their biosynthesis under the assayed conditions.

It is worth to emphasise that T-2 and HT-2 production by F. langsethiae in media amended with the two examined azoles was higher at $0.96 \mathrm{a}_{w}$ than at $0.98 \mathrm{a}_{\mathrm{w}}$. These results suggest that fungal sensitivity to these fungicides increases and toxin production is reduced in media with $0.98 \mathrm{a}_{\mathrm{w}}$, which is more favourable to growth. In cereals, even during pre-harvest, $a_{w}$ rarely reaches values higher than 0.96 . Hence, special attention should be paid to the effect that sub-inhibitory concentrations of these fungicides have on the production of $\mathrm{T}-2$ and HT-2 toxins by $F$. langsethiae in crops. In the assays performed in the media amended with low doses of the two azoles the levels of T-2 and HT-2 increased under some conditions. Studied carried out with strains of different fungal species, from diverse geographical origin and isolated from different host also aim that mycotoxin production in presence of sub-inhibitory concentrations of some fungicides can be boosted under water or thermal stress conditions (Medina et al., 2007a, 2007b; Ramírez et al., 2004). However, $E_{50}$ or $E_{90}$ was not determined or the species $F$. langsethiae was not included in these studies. 
Unfortunately, as far as we know, there are not previous studies on EDs 50 and 90 of the assayed fungicides on mycotoxigenic fungi, which makes the discussion of the obtained results difficult.

Production of T-2 and HT-2 toxins was dependent on the type of fungicide and its dose, temperature, $a_{w}$ and strain. The presence of any of the three fungicides produced a general decrease in the accumulation of the two toxins in cultures even at the lower doses taking the controls as references. In fungicide-containing cultures, toxin concentration generally decreased with temperature at a given dose but some exceptions were found; for example, with tebuconazole and prochloraz, HT-2 level was higher at $20{ }^{\circ} \mathrm{C}$ than at $25{ }^{\circ} \mathrm{C}$ if $\mathrm{a}_{\mathrm{w}}$ was 0.96 . At $0.96 \mathrm{a}_{\mathrm{w}}$, especially at $15{ }^{\circ} \mathrm{C}$, comparable levels of T-2 and HT-2 toxin were produced by strain 2004-59. Some authors have suggested that a biotransformation of T-2 into HT-2 might occur (Lattanzio et al., 2009) and this could be boosted under conditions of physicochemical stress. This may explain, at least in part, the fact that natural oats samples contaminated with levels of HT-2 higher than T-2 have been found (Edwards, 2009; Langseth and Rundberget, 1999).

Studies on the efficacy of fenpropimorph and azoles against phytopathogenic and mycotoxigenic fungi are very necessary not only for control of these fungi and mycotoxins in crops but also because, especially, the azoles are extensively applied in agriculture and medicine. A relationship between the development of azole resistance in agriculture and the development of azole resistance in clinical practice may exist. It has been reported that treatment of the maize pathogen $C$. graminicola with an agricultural azole causes cross-resistance to medical azoles and boosts caspofungin, amphotericin B, and nystatin efficacy (Serfling et al., 2007). Moreover, it has been described that tebuconazole increased T-2 toxin levels in rye and winter triticale infested with Fusarium spp. with respect to untreated cereals (Mankeviciene et al., 2008). Deoxynivalenol (DON) production was also increased in barley crops treated with this fungicide (Malachova et al., 2010). Prothioconazole, another triazole fungicide, was found to trigger DON biosynthesis when added at sub lethal doses in cultures of $F$. graminearum (Audenaert et al., 2010). Therefore, it is very necessary to perform additional 
studies on the influence that ecological factors and sub-inhibitory doses of the most commonly used agricultural antifungal agents have not only on the development of fungal resistance but also on mycotoxin production. So far, the last aspect has been very scarcely investigated and no study has been published regarding $F$. langsethiae and production of T-2 and HT-2.

\section{Acknowledgements}

The authors wish to thank financial support from FEDER and Spanish Government "Ministerio de Ciencia e Innovación (MICINN)" (Projects AGL2007-66416-C05-01/ALI and AGL2010-22182-C04-03/ALI). Eva M. Mateo is also grateful to MICINN for a grant to perform a research visit in the Applied Mycology Group, Cranfield University (UK) and for a PhD grant. Bayer CropScience, BASF Crop Protection and Industrias Afrasa, S.A. are acknowledged for gifts of the fungicide formulations used in the present study.

\section{References}

Adler, A., Torp, M., 2004. The European Sporotrichiella project: A polyphasic approach to the biology of a new Fusarium species. International Journal of Food Microbiology 95, 241-245.

Aldred, D., Magan, N., 2004. Prevention strategies for trichothecenes. Toxicology Letters 153, 165-171.

Audenaert, K., Callewaert, E., Höfte, M., De Saeger, S., Haesaert, G., 2010. Hydrogen peroxide induced by the fungicide prothioconazole triggers deoxynivalenol (DON) production by Fusarium graminearum. BMC Microbiology 10, 112.

Beasley, V.R. (Ed.), 1989. Trichothecene Mycotoxicosis: Pathophysiologic effects, vols. 1 and 2. CRC Press, Boca Raton, Florida.

Campagnac, E., Fontaine, J., Lounès-Hadj Sahraoui, A., Laruelle, F., Durand, R., Grandmougin-Ferjani, A., 2009. Fenpropimorph slows down the sterol pathway and the development of the arbuscular mycorrhizal fungus Glomus intraradices. Mycorrhiza 19:365-374.

Canady, R.A., Coker, R.D., Egan, S.K., Krska, R., Olsen, M., Resnik, S., Schlatter, J., 2001. T-2 and HT-2 toxins. Safety Evaluation of Certain Mycotoxins in Food, FAO Food and Nutrition Paper 74. In: WHO (Ed.), WHO Food Additives Series 47, Geneve, Switzerland, pp. 557-680. 
Debieu, D., Gall, C., Gredt, M., Bach, J., Malosse, C., Leroux, P. 1992. Ergosterol biosynthesis and its inhibition by fenpropimorph in Fusarium species. Phytochemistry 3, 1223-1233.

Debieu, D., Bach, J., Lasseron, A., Arnold, A., Brousset, S., Gredt, M., Taton, M., Rahier, A., Malosse, C., Leroux, P., 2000. Inhibition of ergosterol biosynthesis by morpholine, piperidine, and spiroketalamine fungicides in Microdochium nivale: effect on sterol composition and sterol $\Delta 8 \rightarrow \Delta 7$-isomerase activity. Pesticide Biochemistry and Physiology 67, 85-94.

D'Mello, J.P.F., Macdonald, A.M.C., Bonte, L., 1997. The effects of difenoconazole on 3-acetyldeoxynivalenol synthesis by Fusarium culmorum: implications for cereal quality. In: Crop Protection and Food Quality: Meeting Customers Needs, Proceedings of BCPC and ANPP Conference, Kent, UK, pp. 463-466.

D’Mello, J.P.F., Macdonald, A.M.C., Postel, D., Dijksma, W.T.P., Dujardin, A., Placinta, C.M., 1998. Pesticide use and mycotoxin production in Fusarium and Aspergillus phytopathogens. European Journal of Plant Pathology 104, 741-751.

Edwards, S.G., 2004. Influence of agricultural practices on fusarium infection of cereals and subsequent contamination of grain by trichothecene mycotoxins. Toxicology letters 153, 29-35.

Edwards, S.G., 2007. Investigation of Fusarium mycotoxins in UK barley and oat production. HGCA Project Report No. 415. London: HGCA.

Edwards, S.G., 2007b. Investigation of Fusarium mycotoxins in UK wheat production. HGCA Project Report No. 413. London: HGCA.

Edwards, S.G., 2009a. Fusarium mycotoxin content in UK organic and conventional wheat. Food Additives and Contaminants 26, 496-506.

Edwards, S.G., 2009b. Fusarium mycotoxin content in UK organic and conventional oats. Food Additives and Contaminants 26,1063-1069.

Edwards, S.G., 2009b. Fusarium mycotoxin content in UK organic and conventional barley. Food Additives and Contaminants 26,1185-1190.

European Commission, 2006. Commission Regulation (EC) No 1881/2006 of 19 December, 2006 setting maximum levels for certain contaminants in foodstuffs. Official Journal of the European Union L364, 5.

Hewitt, A.F., 1998. Fungicides in Plant Protection. CAB International, Wallingford.

Hope, R.J., Colleate, A., Baxter, E.S., Magan, N., 2002. Interactions between environmental stress and fungicides effect growth and mycotoxin production by Fusarium culmorum isolates from wheat grain. European Journal of Plant Pathology 108, 685-690. 
Imathiu, S.M., Ray, R.V., Back, M., Hare, M. C., Edwards, S.G., 2009. Fusarium langsethiae pathogenicity and aggressiveness towards oats and wheat in wounded and unwounded in vitro detached leaf assays. European Journal of Plant Pathology 124,117-126.

Joffe, A.Z., 1986. Fusarium Species: Their Biology and Toxicology. John Wiley and Sons, New York. 588 pp.

Kokkonen, M., Ojala, L., Parikka, P., Jestoi, M., 2010. Mycotoxin production of selected Fusarium species at different culture conditions. International Journal of Food Microbiology 143, 17-25.

Langseth, W., Rundberget, T., 1999. The occurrence of HT-2 toxin and other trichothecenes in Norwegian cereals. Mycopathologia 147, 157-165.

Lattanzio, V.M.T., Solfrizzo, M., Visconti, A., 2009. Enzymatic hydrolysis of T-2 toxin for the quantitative determination of total T-2 and HT-2 toxins in cereals. Analytical and Bioanalytical Chemistry 395, 1325-1334.

Leroux, P., 2003. Mode of action of agrochemicals towards plant pathogens. Comptes Rendus Biologies 326, 9-21.

Llorens, A., Mateo, R., Hinojo, M.J., Logrieco, A., Jiménez, M., 2004a. Influence of the interactions among ecological variables in the characterization of zearalenone producing isolates of Fusarium spp. Systematic and Applied Microbiology 27, 253-260.

Llorens, A., Mateo, R., Hinojo, M.J., Jiménez, M., 2004b. Influence of environmental factors on the biosynthesis of the type $B$ trichothecenes by isolates of Fusarium spp. from Spanish crops. International Journal of Food Microbiology 94, 43-54.

Logrieco, A., Visconti, A. (eds). 2004. An overview on toxigenic fungi and mycotoxins in Europe. Kluwer Academic Publishers, Dordrecht, The Netherlands, pp. 252.

Magan, N., Aldred, D., 2007. Post-harvest control strategies: Minimizing mycotoxins in the food chain. International Journal Food Microbiology 119, 131-139.

Magan, N., Hope, R., Colleate, A., Baxter, E.S., 2002. Relationship between growth and mycotoxin production by Fusarium species, biocides and environment. European Journal of Plant pathology 108, 685-690.

Magan, N., Medina, A., Aldred, D., 2011. Possible climate-change effects on mycotoxin contamination of food crops pre- and postharvest. Plant Pathology 60, 150-163.

Malachova, A., Cerkal, R., Ehrenbergerova, J., Dzuman, Z., Vaculova, K., Hajslova, J., 2010. Fusarium mycotoxins in various barley cultivars and their transfer into malt. Journal of the Science of Food and Agriculture 90, 2495-2505. 
Mankeviciene, A., Gaurilcikiene, I., Suproniene, S., 2008. The infestation of winter rye and triticale grain with Fusarium as affected by fungicide. Proc. of the 3rd Int. FHB Symposium, Szeged, Hungary. Cereal Research Communications 36, Suppl.B 6, 683-688.

Marcireau, C., Guilloton, M, Karst, F., 1990. In vivo effects of fenpropimorph on the yeast Saccharomyces cerevisiae and determination of the molecular basis of the antifungal property. Antimicrobial Agents and Chemotherapy 34, 989-993.

Matthies, A., Walker, F., Buchenauer, H., 1999. Interference of selected fungicides, plant growth retardants as well as piperonyl butoxide and 1-aminobenzotriazole in trichothecene production of Fusarium graminearum (strain 4528) in vitro. Journal of Plant Diseases and Protection 106, 198-212.

Medina, A., Mateo, R., Valle-Algarra, F.M., Mateo. E., Jiménez, M., 2007a. Effect of carbendazim and physicochemical factors on the growth and ochratoxin $A$ production of Aspergillus carbonarius isolated from grapes. International Journal of Food Microbiology 119, 230-235.

Medina, A., Jiménez, M., Mateo, R., Magan, N., 2007b. Natamycin efficacy for control of growth and ochratoxin production by Aspergillus carbonarius isolates under different environmental regimes. Journal of Applied Microbiology 103, 22342239.

Medina, A., Valle-Algarra, F.M., Jiménez, M., Magan, N., 2010a. Different sample treatment approaches for the analysis of T-2 and HT-2 toxins from oats-based media. Journal of Chromatography B 878, 2145-2149.

Medina, A., Magan, N. 2010b. Comparisons of water activity and temperature impacts on growth of Fusarium langsethiae strains from northern Europe on oat-based media. International Journal of Food Microbiology 142, 365-369.

Medina, A., Magan, N., 2011. Temperature and water activity effects on production of T-2 and HT-2 by Fusarium langsethiae strains from north European countries. Food Microbiology 28, 392-398.

Moss, M.O., Frank, J.M., 1985. Influence of the fungicide tridemorph on T-2 toxin production by Fusarium sporotrichioides. Transactions of the British Mycological Society $84,585-590$.

Mullenborn, C., Steiner, U., Ludwig, M., Oerke, U-C., 2008. Effect of fungicides on the complex of Fusarium species and saprophytic fungi colonizing wheat kernels. European Journal of Plant Pathology 120, 157-166.

Pateraki, M., Dekanea, A., Mitchell, D., Lydakis, D., Magan, N., 2007. Influence of sulphur dioxide, controlled atmospheres and water availability on in vitro 
germination, growth and ochratoxin A production by strains of Aspergillus carbonarius isolated from grapes. Postharvest Biology and Technology 44, 141149

Placinta, C.M., Macdonald, A.M.C., D’Mello, J.P.F., Harling, R., 1996. The influence of carbendazim on mycotoxin production in Fusarium sporotrichioides. In: Proceedings of The Brighton Crop Protection Conference British Crop Protection Council, Farnham, UK, pp. 415-416.

Prelusky, D.B., Rotter, B.A., Rotter, R.G., 1994. Toxicology of mycotoxins. In: Miller, J.D., Trenholm, H.L. (Eds.), Mycotoxins in grain: Compounds other than aflatoxin. Eagan Press, St. Paul, pp. 359-404.

Ramírez, M.L., Chulze, S., Magan, N., 2004. Impact of environmental factors and fungicides on growth and deoxynivalenol production by Fusarium graminearum isolates from Argentinian wheat. Crop Protection 23, 117-125

Ramírez, M.L., Chulze, S., Magan, N., 2006. Temperature and water activity effects on growth and temporal deoxynivalenol production by two Argentinean strains of Fusarium graminearum on irradiated wheat grain. International Journal of Food Microbiology 106, 291-296.

Schmidt, H., Niessen, L., Vogel, R.F., 2004. AFLP analysis of Fusarium species in the section Sporotrichiella-evidence for $F$. langsethiae as a new species. International Journal of Food Microbiology 95, 305-319.

Schuhmacher-Wolz, U., Heine, K., Schneider, K., 2010. Report on toxicity data on trichothecene mycotoxins HT-2 and T-2 toxins. CT/EFSA/CONTAM/2010/03. Available online: http://www.efsa.europa.eu/en/scdocs/scdoc/65e.htm?WT.mc_ id $1 \frac{1}{4}$ EFSAHL01\&emt $1 \frac{1}{4} 1$.

Scudamore, K.A., Baillie, H., Patel, S., Edwards S.G., 2007. Occurrence and fate of Fusarium mycotoxins during commercial processing of oats in the UK. Food Additives and Contaminants 24, 1374-1385.

Scudamore, K.A., Patel, S., Edwards, S.G., 2009. HT-2 toxin and T-2 toxin in commercial cereal processing in the United Kingdom, 2004-2007. World Mycotoxin Journal 2, 357-365.

Serfling, A., Wohlrab, J., Deising, H.B., 2007. Treatment of a clinically relevant plantpathogenic fungus with an agricultural azole causes cross-resistance to medical azoles and potentiates caspofungin efficacy. Antimicrobial Agents and Chemotherapy 51, 3672-3676.

Thrane, U., Adler, A., Clasen, P.-E., Galvano, F., Langseth, W., Lew, H., Logrieco, A., Nielsen, K.F., Ritieni, A., 2004. Diversity in metabolite production by Fusarium 
langsethiae, Fusarium poae and Fusarium sporotrichioides. International Journal of Food Microbiology 95, 257-266.

Torp, M., Adler, A., 2004. The European Sporotrichiella Project: A polyphasic approach to the biology of new Fusarium species. International Journal of Food Microbiology 95, 257-266.

Torp, M., Langseth, W., 1999. Production of T-2 toxin by a Fusarium resembling Fusarium poae. Mycopathologia 147, 89-96.

Torp, M., Nirenberg, H.I., 2004. Fusarium langsethiae sp. nov. on cereals in Europe. International Journal of Food Microbiology 95, 247-256.

Tzatzarakis, M.N., Tsatsakis, A.M., Charvalos, E., Vakalounakis, D., 2001. Activities of amphotericin, clotrimazole, econazole, miconazole and nystatin against Fusarium oxysporum. Journal of Environmental Science and Health, Part B 36, 331-340.

Wilson, A., Simpson, D., Chandler, E., Jennings, P., Nicholson, P., 2004. Development of PCR assays for the detection and differentiation of Fusarium sporotrichioides and Fusarium langsethiae. FEMS Microbiology Letters 233, 69-76.

Xu, X.M., Parry, D.W., Nicholson, P., Thomsett, M.A., Simpson, D., Edwards, S.G., et al. 2005. Predominance and association of pathogenic fungi causing fusarium ear blight in wheat in four European countries. European Journal of Plant Pathology 112, 143-154.

Yli-Mattila, T., Mach, R.L., Alekhina, I.A., Bulat, S.A., Koskinen, S., Kullnig-Gradinger, C.M., Kubicek, C.P., Klemsdal, S.S., 2004. Phylogenetic relationship of Fusarium langsethiae to $F$. poae and $F$. sporotrichioides as inferred by IGS, ITS and htubulin sequences and UP-PCR hybridization analysis. International Journal of Food Microbiology 95, 267-285.

Yli-Mattila, T., Paavanen-Huhtala, S., Parikka, P., Hietaniemi, V., Jestoi, M., Gagkaeva, T., Sarlin, T., Haikara, A., Laaksonen, S., Rizzo, A., 2008. Real-time PCR detection and quantification of Fusarium poae, $F$. graminearum, $F$. sporotrichioides and $F$. langsethiae as compared to mycotoxin production in grains in Finland and Russia. Archives of Phytopathology and Plant Protection $41,243-260$. 


\section{Figure captions}

Fig. 1. Growth rates (GR) of two strains of $F$. langsethiae cultured on oat-based medium at different water activities and temperatures. Error bars mean standard errors. A) strain 2004-59; B) strain M562.

Fig. 2. Growth rates ( $\mathrm{GR}, \mathrm{mm} /$ day) of two strains of $F$. langsethiae on oat-based medium supplemented with different doses of fenpropimorph.

Fig. 3. Growth rates (GR, mm/day) of two strains of $F$. langsethiae on oat-based medium supplemented with different doses of prochloraz and tebuconazole.

Fig. 4. Accumulation of T-2 and HT-2 toxins in (control) cultures of two strains of $F$. langsethiae in oat-based medium after 10 days incubation at 0.96 and $0.98 a_{w}$ and at 15,20 and $25^{\circ} \mathrm{C}$.

Fig. 5. Change of levels of T-2 and HT-2 toxins in oat-based medium cultures of two strains of $F$. langsethiae with different doses of fenpropimorph at 0.98 and $0.96 \mathrm{a}_{\mathrm{w}}$ and 15, 20 and $25^{\circ} \mathrm{C}$. Incubation time was 10 days. Please refer to Figure 4 for control data.

Fig. 6. Change of levels of T-2 and HT-2 toxins in oat-based medium cultures of two strains of $F$. langsethiae with different doses of prochloraz at 0.98 and $0.96 \mathrm{a}_{\mathrm{w}}$ and 15 , 20 and $25^{\circ} \mathrm{C}$. Incubation time was 10 days. Please refer to Figure 4 for control data.

Fig. 7. Change of levels of T-2 and HT-2 toxins in oat-based medium cultures of two strains of $F$. langsethiae with different doses of tebuconazole at 0.98 and $0.96 \mathrm{a}_{\mathrm{w}}$ and 
15,20 and $25^{\circ} \mathrm{C}$. Incubation time was 10 days. Please refer to Figure 4 for control data.

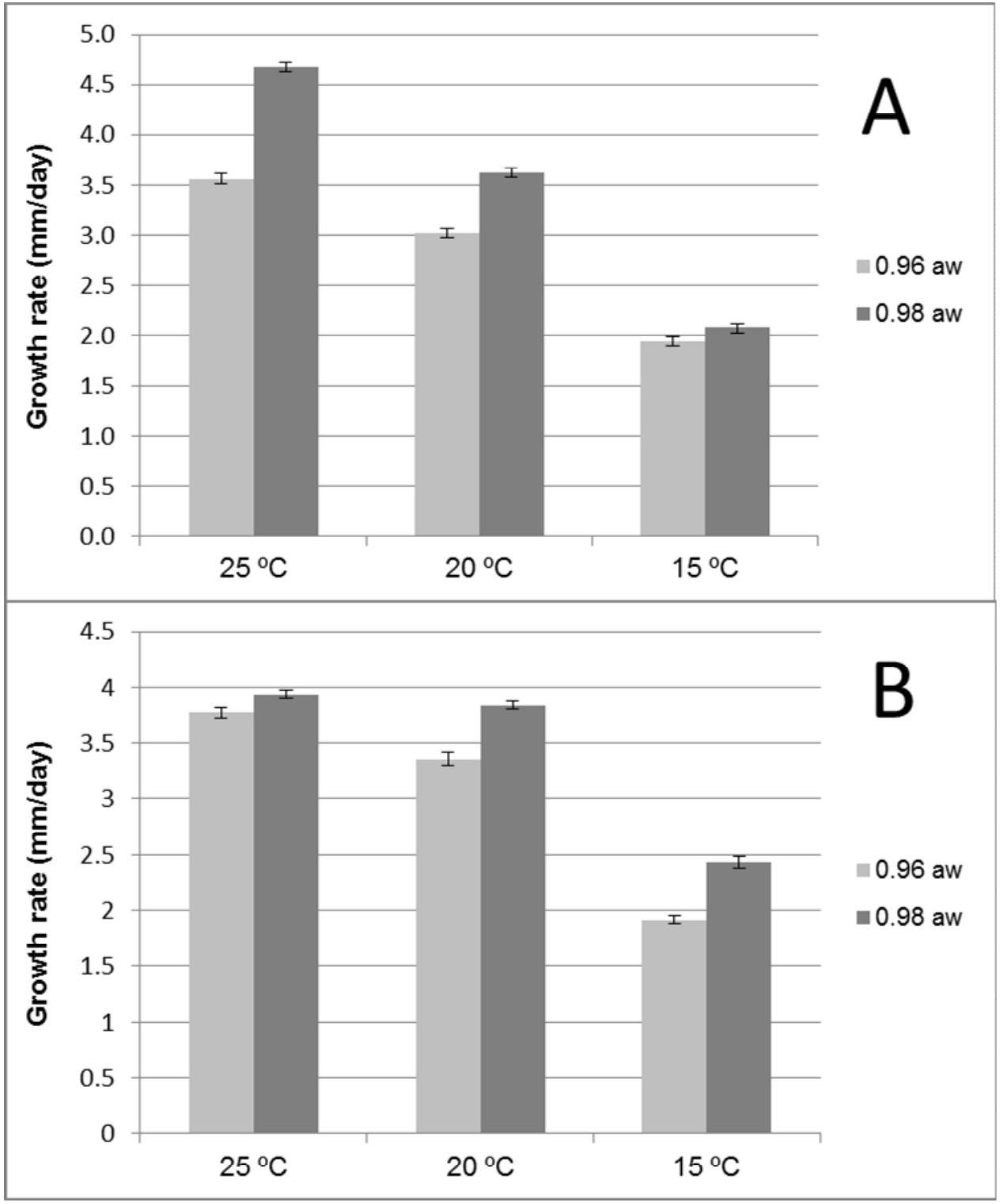

Figure 1 


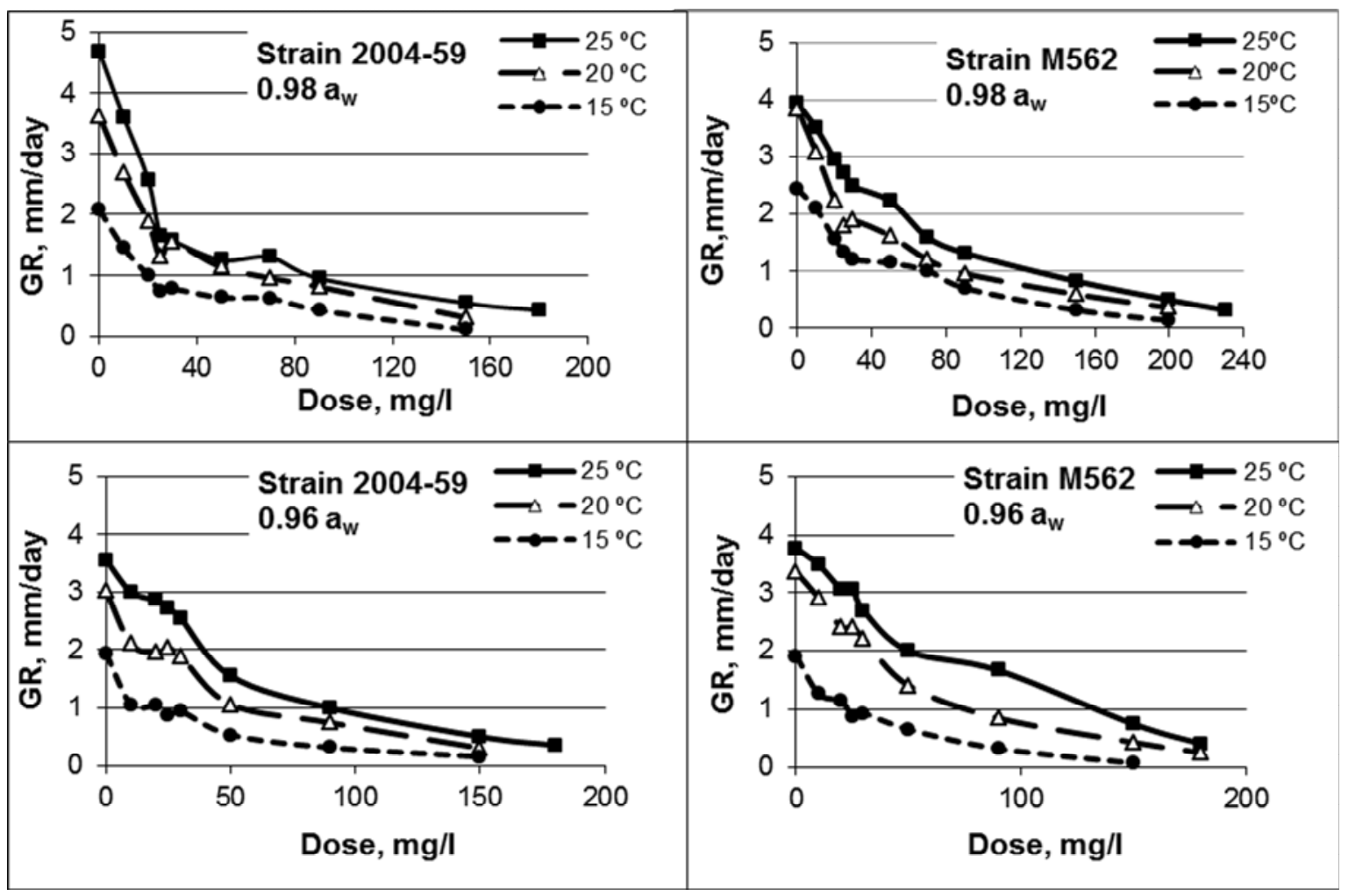

Figure 2. 

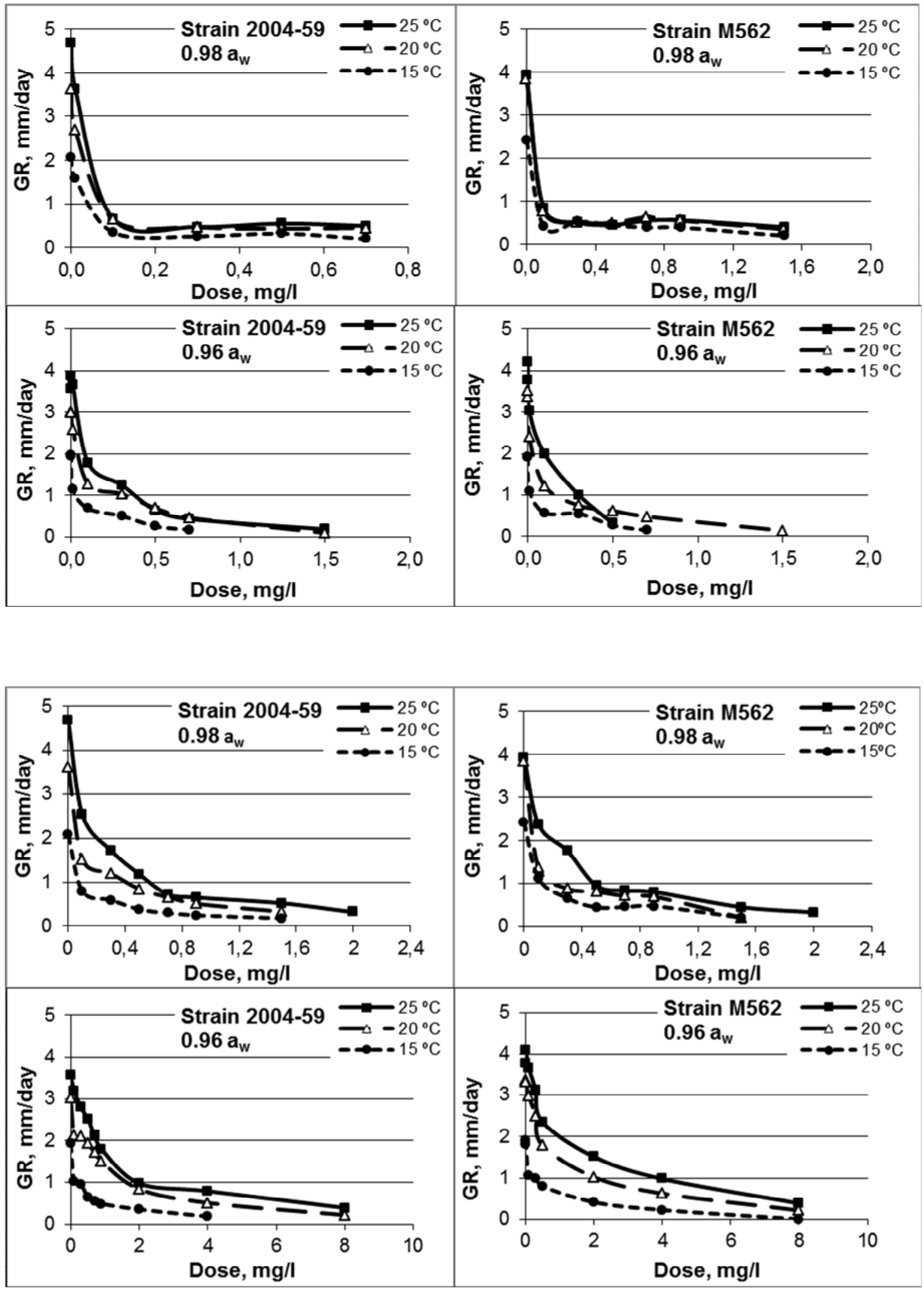

Figure 3. 


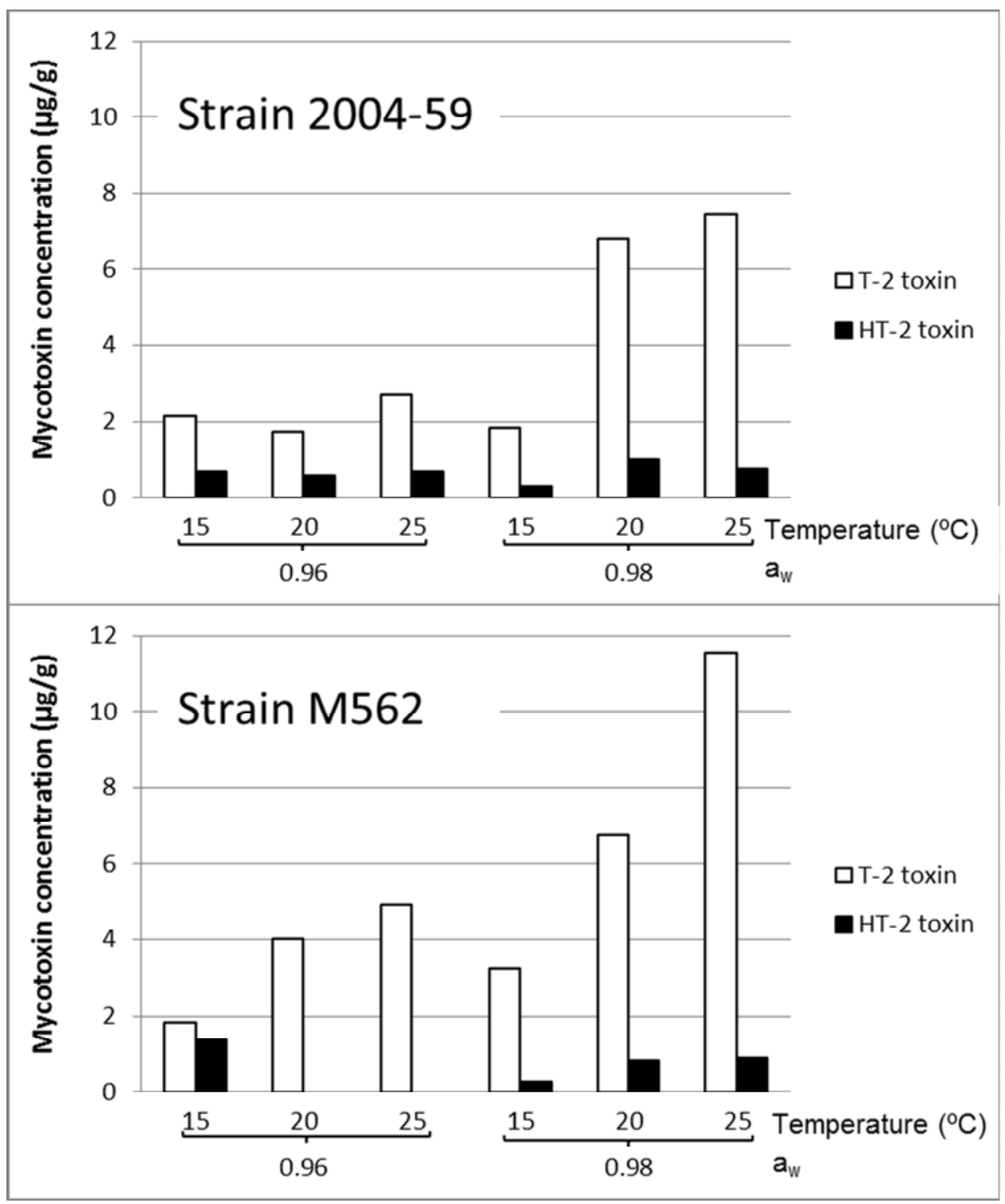

Figure 4. 


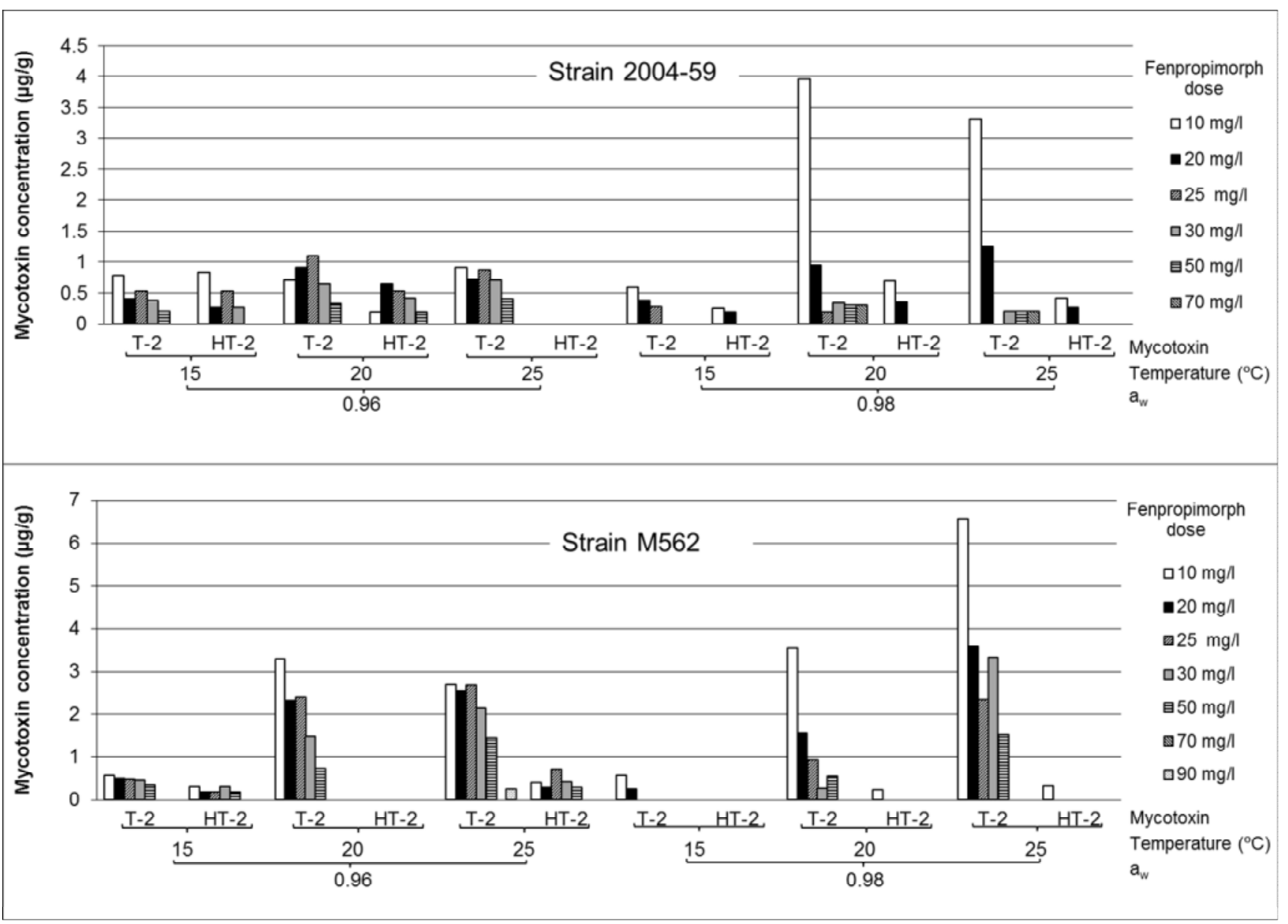

Figure 5. 


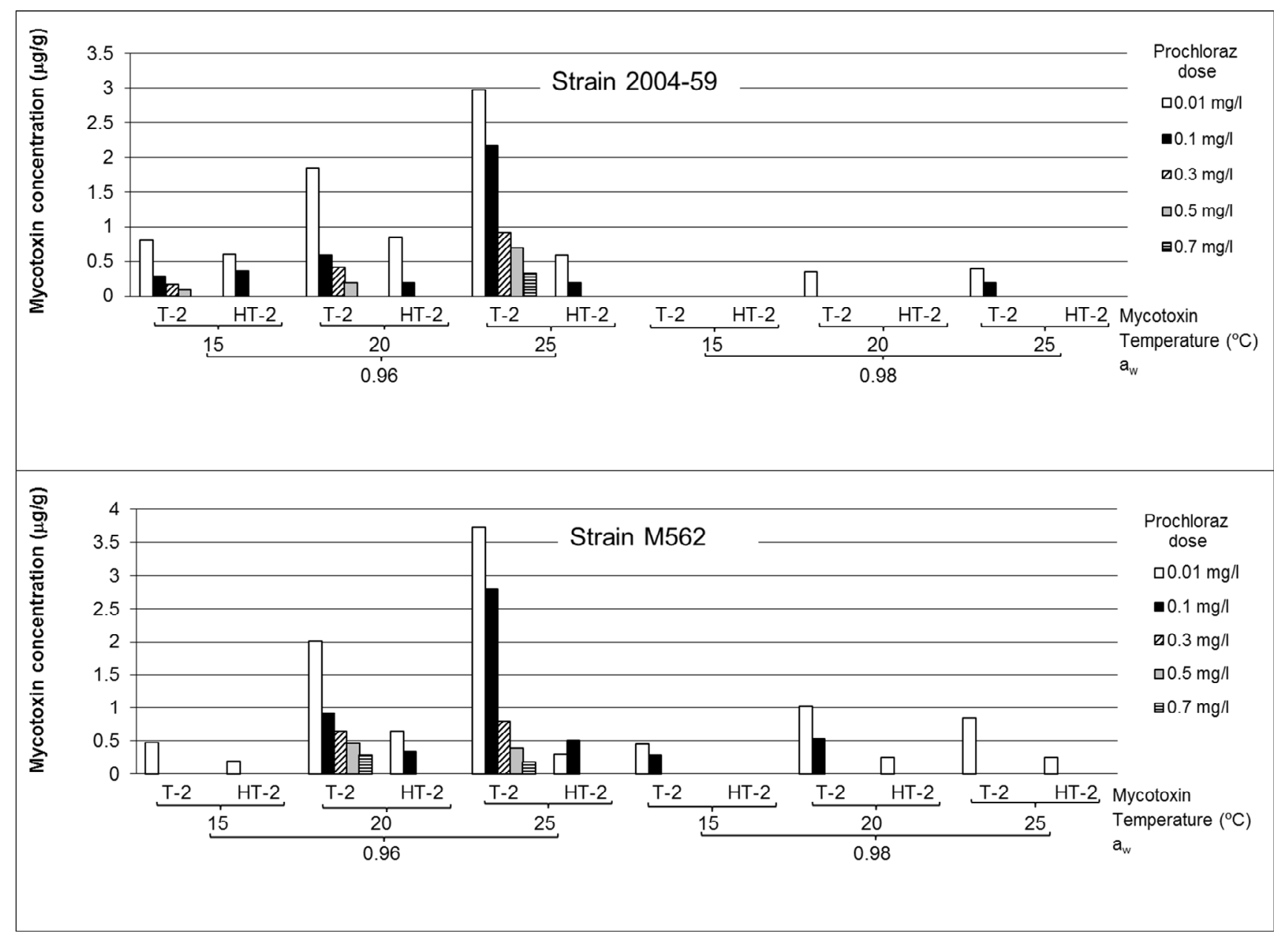

Figure 6. 


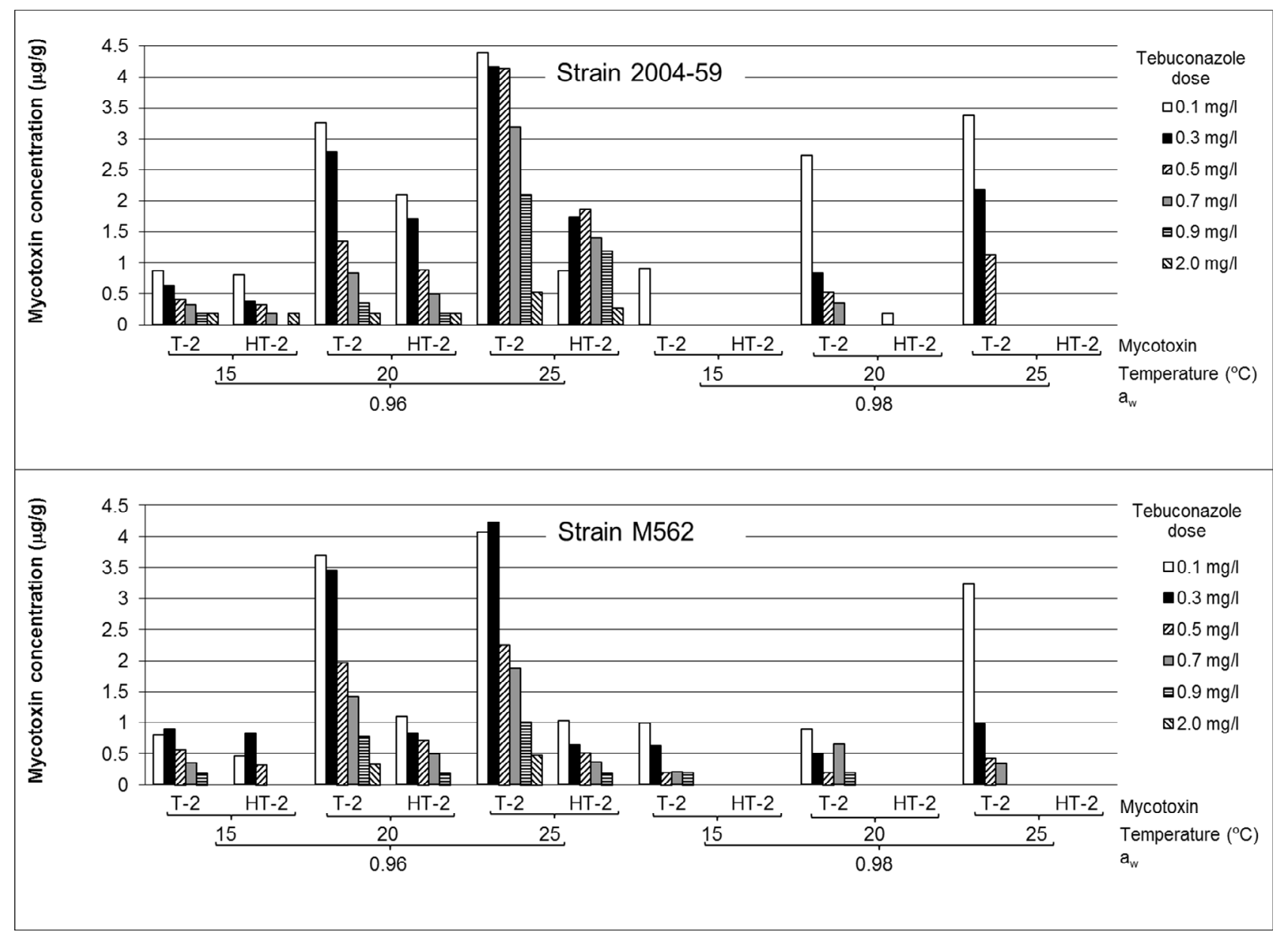

Figure 7. 
